\title{
Pride Parades and Prejudice: Visibility of Roma and LGBTI Communities in Post-Socialist Europe
}

\begin{abstract}
This article argues that public space is important for marginalised communities in order to ensure visibility and presence in public life. Often minority groups are frozen out of democratic procedures which favour majority interests and preferences. This is not to say that minority interests are incompatible with those of the majority but some marginalised groups are not anchored in public space, can suffer discriminatory treatment and lack the ability to control dominant, usually negative, ascriptions of group identity. This article explores two cases of marginalised communities and access to public space in post-socialist Europe: Roma and the LGBTI communities. Both communities have attempted to ensure their presence in public space through 'Pride' parades across Central and Eastern Europe capitals. The purpose of pride parades is to demand rights as citizens, such as equality and respect, and to ensure visibility in public life. On the one hand, visibility is important for LGBTI communities who remain relatively hidden and fear 'coming out', on the other hand, for Roma, who are highly visible, pride offers an opportunity to harness this visibility to challenge prevailing negative stereotypes through an affirmation of group identity.
\end{abstract}

\section{Introduction}

Roma $^{i}$ and LGBTIii communities are two of the most marginalised minority groups in Central and Eastern Europe, and routinely excluded from full citizenship rights. iii Whilst the notion of either a Roma or an LGBTI community is highly contested particularly by those identifying as Roma and LGBTI, this article suggests that some groups have mobilised on the basis of a common identity in order to agitate for societal change. ${ }^{\text {iv }}$ Today, in the midst of political transformations and economic turmoil across post-socialist Europe, legal protections for marginalised communities are under attack and social inclusion remains tenuous. Both communities are discriminated against and sometimes face outright hostility, violence and segregation at the hands of society and the state. Instead of acquiescence there have been attempts to affirm their existence and demand rights and recognition from the majority through mobilisation in public spaces. This is not without its problems: Roma communities are subject to degrading treatment across Central and Eastern Europe, whilst many LGBTI individuals hide their sexual orientation for fear of persecution. This raises a paradox for LGBTI and Roma communities: how to challenge and change treatment by the majority by publicly drawing attention to a stigmatised identity which is both the basis of oppression and the basis for political power (Gamson 1995)? This article is based on research conducted at Roma Pride in Prague in 2014 and Gay Pride in Sofia in 2015 and explores how and why Roma and LGBTI communities have attempted to appropriate public space and the significance of visibility for marginalised communities. It seeks to add a corrective to the conviction that marginalised communities are vulnerable and lack agency by highlighting efforts to challenge marginalisation through visibility. A comparative analysis between Roma and LGBTI 
mobilisation in the post-socialist context reveals how two of the most marginalised communities in Central and Eastern Europe have used public space to affirm a collective identity and participate as equal citizens in the public sphere.

Whilst it is too soon to determine whether pride parades will lead to a fundamental change in societal attitudes, to inclusion in socio-economic and political life and to a reduction of discriminatory treatment of both Roma and LGBTI communities, it does herald an affirmation of presence in public life. It is important to note that gaining visibility is not necessarily about strategic intervention in order to cede immediate legislative changes but should be understood as a public declaration of belonging and an act or performance of citizenship (Isin and Nielsen 2008) with the hope that acceptance or a formal political voice is forthcoming in the longer term. Citizenship is understood here as social practice (Karolewski 2010). Presence in public life is tacitly accepted as a prerequisite for participation for marginalised groups, while having a political voice is commonly believed to ensure substantial equality in public. Once presence and voice is secured, having significant influence allows minorities to enjoy substantive voice as agents of policy-making in their own right (McGarry and Agarin 2014). Roma and LGBTI individuals are citizens of the states in which they reside yet the negative stereotypes of LGBTI and Roma is so pervasive, it means that equal citizenship remains out of reach $^{v}$. Roma and LGBTI individuals are systemically excluded from the polity on the basis of their perceived problematic identity as an excluded 'other', and widely regarded as unwanted or threatening. Visibility is important for those wanting to affirm their belonging to the polity as equal citizens so pride parades are a means to publicly celebrate individual and collective identity as LGBTI or Roma and to participate in the public sphere, an arena which has been closed to Roma and LGBTI individuals in the past. Visibility is not always desirable for marginalised groups, such as radical activists who may want to remain under the radar of state and security agencies, but for individuals whose capacity to access citizenship rights is hindered by a stigmatised group identity, visibility facilitates active citizen participation. It is an act of citizenship which performs the belonging of Roma and LGBTI individuals to wider society. Pride parades provide an opportunity to control the narrative of collective identity maintenance by invoking an affective solidarity and attempting to change the meaning and content of a stigmatised identity by challenging dominant negative stereotypes.

The avenue for visibility is not solely through pride parades and some of these come from outside the state/region, the most significant of which is the EU public sphere. Transnational sources of changes have been fundamental to LGBTI visibility in post-socialist Europe since 1989 , in part, they provide the motivation and material and symbolic resources for the local mobilisation of pride events in the first place. Ayoub (2015) shows that domestic activism is not replaced by transnational activism rather LGBTI groups act as brokers between international and domestic norms and help to frame the message to make it resonate with a particular (domestic) audience (Tarrow 2005). One of the key frames in the promotion of the rights of marginalised communities in post-socialist Europe has been citizenship rights.

Prior to 1989, communities such as Roma and LGBTI were relatively invisible in Central and Eastern Europe. Legislation criminalised homosexual sex and a raft of other anti-gay laws meant that LGBTI individuals remained hidden fearing persecution, whilst for Roma communities, socialism meant assimilation where Roma communities lost much of their cultural specificity including their professions and language (Stewart 1997). The transition to 
democracy brought with it increased opportunities to access the political arena and public sphere through human rights legislation on freedom of association, speech, and assembly as well as non-discrimination on the basis of national or ethnic origin and sexual orientation. Since 1989, the position of Roma has deteriorated with unemployment and illiteracy rates disproportionately high, segregation in schools and housing rife, and Roma subject to demeaning stereotypes including the widespread conflation of Roma/Gypsy culture with criminality (Ringold et al 2005). The carrot and stick of European Union (EU) membership meant that states adopted progressive laws on discrimination and protection of minorities outlined in the Copenhagen criteria (1993), including for Roma (Guglielmo and Waters 2005) and LGBTI communities (Kahlina 2013; Ayoub and Paternotte 2014). Indeed, pride parades have been recognised as a key indicator of human rights and democratisation in the EU'S eastern enlargement policy (Holzhacker 2013) and research has shown how the EU has impacted positively on the development of gay rights movements in Poland (O'Dwyer 2012) and across Central and Eastern Europe (Ayoub 2015).

The transition to democracy and a functioning market economy generated widespread anxieties with Roma communities frequently used as scapegoats for a range of socioeconomic and political ills throughout the 1990s. Presence in public life is not without its drawbacks as Ungar (2000: 62) notes 'growing visibility and shift into political activism sparked backlashes' against LGBTI communities. With growing urbanisation, education and increased access to media outlets, LGBTI communities have grown more confident in articulating their interests publicly. Gay rights activist, Peter Tatchell, speaking at Slavic Pride in 2009 said: 'Through this media visibility, we are helping to normalise queer existence. After our successive gay protests in Moscow since 2006, people are less shocked about homosexuality'. However, once communities place their heads above the parapets and demand rights it is difficult to evade fire thus drawing attention to the rights of the LGBTI individuals has provoked hostility with pride parades events frequently marred by conflict with counter protests organised by neo-Nazi and religious groups. In some states, such as Russia, the discussion of homosexuality in front of children could result in jail (BBC 2013) as lawmakers have sought to curb the increasingly confident and empowered LGBTI community by stoking animosity towards LGBTI individuals. In fact, in Russia, the only gay pride parade which has not provoked homophobic counter protestors, violence and arrests was in 2010 when activists publicised one place for their march but gathered somewhere else for a 'flash mob' and quickly dispersed before police or protestors could intervene (Underwood 2011), which points to risks associated with being too visible. Similarly, in Belarus, the first Gay Pride was held out of sight in the suburbs of Minsk for safety reasons and had no audience, only the parade participants (personal interview with journalist and attendee Nana Håkansson, August 13th 2015). But LGBTI Russians are in a bind: how to challenge state and societal repression whilst lacking the basic rights to assembly and association. In most Central and Eastern European states, repressive legislation on Roma and LGBTI communities is less prevalent but societal attitudes are overwhelmingly negative (EU Commission 2012: 41; 114) 
and this is where the appropriation of public space by marginalised communities can have an

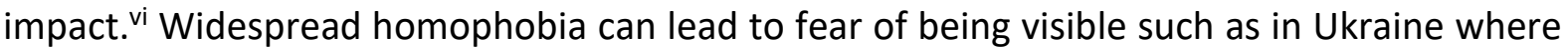
a prominent LGBTI leader does not advocate the organising of large public gay pride demonstrations because Ukrainian society is 'not ready' for them (Martsenyuk 2012: 56) but given the fact that attitudes towards homosexuality have not changed since independence (Ibid) one could argue that invisibility as a strategy of survival could result in the perpetuation of stigma.

Pride is a global movement instigated and associated most clearly with the LGBTI community. In 1969, police raided the Stonewall Inn in New York which led to riots in the streets involving the LGBTI community and the police. To draw attention to police brutality, social stigma and marginalisation, gay pride was held for the first time in 1970 to turn what many in the community considered to be a collective shame into collective pride. A key dimension has to bring sex into the public sphere (Berlant and Warner 2003) to draw attention to inequalities and rights regarding sex. The movement has since grown and today pride parades are held in every continent and have helped to make visible the LGBTI community and to transform the public perception of LGBTI communities leading to a concomitant change in laws regarding civil partnership, marriage, blood donation, and adoption. Most legislative changes have been secured in states in North America and Western Europe where pride parades are established and are relatively uncontroversial. Pride has become a symbolic resource and source of influence for LGBTI communities around the world and more recently for other marginalised communities, including Roma, contributing towards a 'politics of visibility' (Kahlina 2013: 16).

The article begins by exploring marginalised communities and public space specifically by outlining how and why marginalised communities appropriate public space in order to challenge societal understandings and to raise awareness of their demands. A discussion of pride and visibility is outlined with reference to historical and contemporary protest movements. The article then explores the two cases in turn: first, the interplay between Roma activism in the national and transnational political context is outlined before a discussion of visibility and Roma Pride in Prague (2014) is outlined; secondly, it will examine LGBTI activism in post-socialist Europe before analysing the significance of visibility for the Pride Parade in Sofia (2015). A comparative discussion in citizenship, public space and visibility reveals the tension for marginalised communities as they seek to affirm their difference, demand recognition whilst attempting to transform public attitudes towards LGBTI and Roma communities. Whilst the article focuses on two different contexts and two different groups it does reveal how public affirmation of collective identity is realised and the importance of visibility to some of the most excluded peoples in post-socialist Europe. The article adds to the growing literature on visibility of marginalised voices in public space and challenges the idea that marginalised voices lack political agency, especially that which is pursued through the performance of citizenship.

\section{Visibility and Public Space}


Not all those who belong to the LGBTI and Roma communities engage in activism, with numbers quite small for both. Those who advocate or engage in activism do not seek to represent their communities because defining the parameters of heterogeneous communities is a task fraught with difficulties, notwithstanding the thorny issue of representation for a porous group. Social movement activists and advocates attempt to foster solidarity internally by uniting the group around a common cause but also seek to raise awareness externally of the multiple issues related to a particular group identity. Suffice to say, even if someone identifies as LGBTI or Roma, it does not mean they will be activists, even though they are likely to benefit from any legislative concessions and changes in attitudes. One key motivation for activism is to promote visibility based on the argument that those who are present in public life are less likely to be ignored or have their interests assumed by policymakers acting on their behalf (Phillips 1998). A lack of visibility is the product of fear, oppression, violence, humiliation, and internalised prejudice. It could also point to selfcensorship in the elaboration of identity or the invisibilising of Roma and LGBTI individuals/citizens through their lack of representation in political debates and marginalised sociocultural status (Ross 2008: 241). Invisibility is certainly more of an issue for LGBTI individuals than Roma which is revealed in a study into discrimination by the EU with a low public perception of discrimination against LGBTI community (EU Commission 2012: 38) compared to how LGBTI individuals actually experience discrimination which is much higher (Fundamental Rights Agency, 2013: 15). For Roma, the issue is that visibility is not on terms of their own choosing with nationalist parties and other groups constructing Roma as a plague, a disease and a parasitic community threatening the fabric of the nation (McGarry 2014), with negative attitudes fuelled by relentless negative coverage in the media. Thus, Roma communities are certainly present in the public sphere but they have been placed there by others (including media and politicians) in order to serve political ends.

So, what is meant by visibility? Certainly it suggests a presence in public life and recognition of existence as the first step and visibility is only possible through citizen participation. Ross (2008: 244) argues that 'coming out into the light and demanding social recognition entails a process of self-affirmation, self-identification and the assumption of a political stance'. This article is not concerned with self-affirmation or self-identity but why marginalised communities use public space to promote visibility and the impact they hope to have. Visibility alone is not enough; the content of visibility is important as the case of stigmatised Roma communities attests. Underwood (2011: 44) notes that visibility is important to fostering acceptance though it can heighten intolerance as marginalised communities attempt to assert their presence in a public space. If visibility is a strategy for acceptance then pride could be counter-productive if it stirs up homophobia, at least in the short term. When communities take control of the visibility process and affirm their status in public, it signifies more than a performance of group identity but carries with it a declaration to be tolerated, understood, and accepted as different. It is citizenship which demonstrates the existence of hidden or marginalised communities in public life. Therefore, we can speak of visibility as a 
process which seeks to challenge the cultural codes (Melucci 1989) and discourses which constrain and denigrate LGBTI and Roma communities. Invisibility suggests a refusal of recognition within broader social, cultural and political discourses which could mean that a community does not exist, indeed is actively denied existence by the majority.

The process of visibility is mediated through public space which can refer to material space such as a city or a virtual space such as social media platforms. Space is something that is 'folded into' social relations through mundane and dramatic activities (Harvey 1996). Communities attempt to appropriate public space in order to control the process of visibility thus space is a resource harnessed and transformed through political action. To be clear, visibility brings communities and identities into the open and requires others to take notice but more than this the interaction between people and space shapes social identities (Massey 1998). Space does not function as an actor or a political subject but is used by individuals and groups to claim, sustain, or propagate power, usually the state's (Painter 2010). In postsocialist Europe public space is used by the state to affirm national and ethnic identity belongings but other identity groups then struggle to organise publicly. Using space as a medium is a power strategy (Sack 1986) to exert influence. LGBTI and Roma communities do not seek to control public space in the same way that demonstrators at in Istanbul in 2013 appropriated Gezi Park to challenge the government (Akcali and Korkut 2015) rather pride parades signify attempts to use urban spaces to influence cultural codes and discourses to affirm a group identity. Visibility here as a process is episodic rather than sustained, usually once a year in the capital city or a regional city and brings together a diverse range of individuals. ${ }^{\text {vii }}$ Individuals perform an act of citizenship by participating in the public space and affirming their identity as Roma or as LGBTI. The idea that public space belongs solely to the state or government has been challenged by successive social movements across the world so that increasingly public space is regarded as an interpersonal sphere of sociability (Loftland 1998) which is, in theory, accessible to many different people for a range of activities (Kärrholm 2007). The appropriation of public space is non-controversial in states which uphold human rights such as freedom of assembly and freedom of speech, which extends to most post-socialist states, until groups which heretofore have been invisible attempt to use public space to demand recognition. Pride is more than simply a celebration of the community but is an outward looking intervention, a moment of rupture which challenges the shackles of invisibility. The article will examine how Roma Pride in Prague (2014) and Gay Pride in Sofia (2015) use public space and promote visibility and addresses some of the tensions inherent in visibility such as increased attention and hostility as well as the simultaneous mobilisation and transformation of a stigmatised group identity.

Space has been recognised as vitally important to marginalised groups as they attempt to ensure a sense of security to assuage perceived vulnerability. For example, Pickering et al (2011) show that young people, lacking their own spaces, are present in public spaces such as shopping centres, parks, city squares and streets and through habitual presence these spaces foster a sense of identity. Similar to young people, when Roma are present in public space 
they are described as being unsightly, unwanted and undesirable, and perceived by the majority as potentially dangerous. Marginalised communities often appropriate or inhabit a space for cultural and material production, for example, gay bars, cafes, or saunas, where members can meet in a 'safe space' where activities are out of sight and in theory preclude the possibility of hostility. Protection is ensured through invisibility. For Roma communities living in ghettos, settlements, villages, towns, and apartment blocks surrounded by other Roma, some protection is provided in numbers. In both cases, the marginalised community reinforces differential status with invisibility, which has a number of negative implications, including that the majority believes invisible communities are secretive and untrustworthy or worse, that they do not exist. Invisibility is a strategy for some but sits uncomfortably with others. Roma and LGBTI individuals are frequently visible, deploying cultural tropes and aesthetics such as clothes and hairstyles as well as bodily aesthetics to signal to others within and outside of the community who they are. This could be interpreted as an act of defiance or simply an embracing of one's identity. Pride parades are deliberate and public acts of citizenship by marginalised communities who appropriate public space to become visible and foster a collective sense of solidarity and identity.

\section{Roma Pride in Prague (2014)}

A stigmatised group's presence in the public sphere is regulated by multiple institutions and discourses which conspire to construct a negative image of the group which is consolidated over time. It is extremely difficult for groups such as Roma to gain access to media outlets, such as newspapers or television, which will help combat negative ascriptions. Plaut (2012: 57-58) points to how Roma are often represented in the media as either criminals who perpetrate crime or as victims who are persecuted. Rarely do Roma occupy the middle ground: their ethnicity is mentioned so that the reader can determine whether Roma are 'good' or 'bad'. In policy-making Roma are presented as a problem community requiring a solution. Roma are frequently frozen out of policy deliberations at the national and supranational levels and do not have a voice of their own (McGarry 2010). It is not entirely fair to say that Roma are not present or visible in the public sphere, the issue is that this presence is owned and controlled by others such as political parties (mainstream and extreme) and the media which paints an unfavourable portrait of the community. Phillips (1998) maintains that presence is enough to ensure that minority groups will be listened to or at least that their interests cannot be ignored but this does not always work in pracice. The nascent Roma Pride movement certainly seeks to address the presence and visibility of Roma across Europe, but it also aspires to provide Roma with a voice, something which is conspicuously absent at local, national and international levels. Thus, Roma Pride is more than an attempt to ensure presence in the public sphere: it signifies an attempt to resist exclusion by the majority and to affirm cultural validity. But it is unclear how Roma Pride will help improve the very real socio-economic and political marginalisation of Roma in every state in which they reside. Moreover, there is the potential for Roma Pride to galvanise opponents such as the far-right in the same way that religious groups and extremists have mobilised against gay pride parades in Central and Eastern Europe.

In the last five years, a phenomenon has emerged and, whilst new, it has the potential to debunk stereotypes and transform the meaning of Romani group identity as well as to forge 
a political consciousness for Roma across Europe. The first Roma Pride was a loosely organised series of events across Europe on October $1^{\text {st }} 2011$ led by a transnational NGO, the European Grassroots Antiracist Movement (EGAM). Events such as speeches/lectures, exhibitions, public awareness campaigns, concerts, gatherings in public spaces, and open access to an illegal Roma settlement were held in Belgium, Bulgaria, Croatia, Denmark, France, Italy, Norway, and Romania (EGAM 2011a). Two Pride marches occurred, in France and Romania: the march in Bucharest was called the "Dignity March" and was a celebration of Romani heritage and culture, participants dressed in colourful traditional clothing but political slogans and messages were not prominent. In a message of support from George Soros (who established and continues to fund the Open Society Institute) played to those assembled he argues: 'You do not seek to disappear into the general population but want to retain your identity as Roma. That is the best way to challenge the mistreatment to which you are subjected and to shatter the negative stereotypes which prevail about you in the general public' (Soros, 2011). On the eve of the first Roma Pride, EGAM published a manifesto signed by representatives from Roma NGOs and anti-racism NGOs from 21 states entitled 'Dosta!' ('Enough!'). The manifesto notes the current climate of fear and violence suffered by Roma across Europe and draws parallels to the experience of the gay community in the USA in the 1960s who also endured demeaning representations, marginality, being denied the same rights as other citizens, and who frequently suffered violence at the hands of individuals and the police, because of who they were (EGAM 2011b). The creation of Roma Pride is clearly based on the persecution which they are facing and draws upon the victim status of Roma across Europe: 'we will march at the heart of the main European cities to raise awareness about and to denounce the racism and the racial discriminations Roma people are today victim of all over Europe' (EGAM 2011b).

In 2014, Roma Pride was held in 16 different countries across Europe. It is usually held on the first Sunday of October, unlike gay Pride which is spread across several months in Europe, usually May-August. I attended Roma Pride in Prague having interviewed the organizers of 8 Roma Pride events in 2013 across Europe. Roma are a relatively small population in Czech Republic with approximately 200,000 people considered to be Roma although selfidentification in the national census is much lower $(13,000)$, which is common across Central and Eastern Europe with Roma communities reluctant to declare ethnicity for fear of discrimination. The number of Roma living in and around Prague is quite low with most Roma living in the north and east of the country however, the organisers believed it was important to have a presence in the capital city to draw attention to the issues facing Roma. Buses were hired to bring Roma individuals from the north of Czech to Prague for Roma Pride in 2013 and 2014 (Interview with Miroslov Broz, November 2013).

The Director of Roma Pride in Prague is Ivanka Mariposa Čonková who believes the main purpose of Roma Pride is to promote solidarity amongst Roma but she is not confident that Pride can address the problems facing Roma communities across Europe (Interview on $9^{\text {th }}$ December 2013). The event was co-organised by Konnexe, which is a Czech anti-racist organisation, which is made up of Roma and non-Roma. Significantly, whilst Pride events were held across Europe on the first Sunday of October, the organisers decided to reschedule as they wanted to be present at a neo-Nazi rally targeting Roma communities on the same day, so the event was held the day before. Roma Pride in Prague in 2014 was a series of events and performances held in different parts of Prague. The event ran from early morning and started in the Old Town and after the pride parade a religious service at a church was held 
and was followed by a dance party at a different venue. Several hundred people, including many Romani women dressed in traditional clothing were in attendance in the Old Town Square (Staroměstské náměstí) and attracted a range of media including TV, radio, blogs and newspapers, with Ivanka, in traditional clothes, giving interviews. Many of those present were not Roma but were drawn to the dancing and singing of different Roma and non-Roma groups. A series of speeches closed the first part of Pride before the participants gathered behind a horse drawn carriage which led the pride parade as it snaked through the Old Town. A Roma band played music from the carriage whilst participants chanted slogans such as 'We are human too' to people watching in the streets and across the Charles Bridge. The organisers understand that the Old Square, Old Town and Charles Bridge is populated primarily by tourists and not many 'locals' are there to witness the parade. Whilst this has obvious drawbacks in terms of visibility it does mean that those hostile to the presence of Roma such as neo-Nazis are themselves less visible, the police unwilling to permit an incident in such a high profile public space with so many tourists (similar with LGBTI case). The presence of the police on the parade was minimal and the whole event passed without incident. There were a few calls from the side lines from a few people who registered their dissatisfaction with the parade and they were quickly silenced by other people in the crowd, who appeared to enjoy the celebratory atmosphere of the music. Many of those watching may not have registered the significance of what was happening; a vulnerable group standing together demanding recognition. But the fact that those watching were tourists for the most part meant that the visibility of the parade is negated somewhat as recognition is ruled out. However, it has the advantage of amplifying the voice of Roma and gaining more international attention.

\section{Gay Pride in Sofia (2015)}

Bulgaria introduced a raft of anti-discrimination legislation in order to join the European Union, which it did in 2007. Laws prohibiting discrimination against sexual orientation are codified although public attitudes are still not accepting of diverse sexual minorities. There are no laws regarding civil unions, marriage or same sex adoption in Bulgaria which is not unusual in Central and Eastern Europe. Attitudes towards gay, bisexual and trans people is still negative with unjustified violence being committed and an unwillingness of state institutions to protect LGBTI individuals effectively (Amnesty International 2012).

Gay Pride in Bulgaria is a contentious issue and meets with significant opposition from religious groups and the far right. The first gay pride in Sofia was held in 2008 and was marred by violence. Approximately 60 far rights protestors were arrested as they threw eggs and a petrol bomb at the 100 parade participants (Mudeva 2008). The Socialist Prime Minister Sergei Stanishev said he did not like 'the manifestation and demonstration of such orientations' careful to make a distinction between the visible manifestation and the community itself. According to one participant, in 2010, there were many more police than marchers, most of them in full riot gear, and a phalanx of armoured vehicles escorted protestors on either side of the street (Greenwell 2013). In June 6 2012, Father Evgeni Yanakiev of the Bulgarian Orthodox Church was quoted in the newspaper Standart as saying: 'Our whole society must, in every possible way, oppose the gay parade that is being planned. For this reason, today I appeal to all those who consider themselves Christians and Bulgarians. Throwing stones at gays is an appropriate way' (Dittrich 2012). In 2013, amidst widespread civil unrest in Bulgaria, gay pride was cancelled but the LGBTI people were present in the anti- 
government protests, handing out rainbow flags at public rallies. In early 2014, the right wing party Ataka introduced a bill 'Law on Gatherings, Meetings and Manifestations' which had previously been rejected by the Bulgarian Parliament because it violated EU Human rights regulations, which states: "No meetings or demonstrations can be held with the purpose of public display of homosexual orientation or affiliation," inspired by antigay propaganda legislation in Russia (Littauer 2014). Volen Siderov, the leader of the nationalist party Ataka, said that Pride marches are not only 'an assault on public morality and values,' but also 'represent public incitement to vandalism and antisocial acts' (Littauer 2014). The parade went ahead with around 1000 participants (Bulgarian Helsinki Committee 2014) protected by police however the parade was prevented from passing the Vasil Levski monument in the city centre by a group of counter-protesters from Ataka. In a press release, the human rights NGO, Bulgarian Helsinki Committee, stated: 'The Bulgarian Orthodox Church represented by the Holy Synod condemned the pride, calling it a "march of proud sin". Nationalist political parties also condemned the pride and called upon Bulgarian people to protect their children from this 'parade of lust'. Member of the Parliament from the nationalist and pro-Russian political party of "Ataka" called the event "pederasts march" while sympathisers of the party were chanting 'Kill the pederasts' in the background, surrounded by a cordon of police. Many calls for violence against the pride were also made in social media, mainly on Facebook'.

It could be argued that this is a small but vocal group which is hostile to the LGBTI community but it fuels an atmosphere of fear, prejudice and rejection. One impact is that the community becomes more active online with social media forums acting as hubs for LGBTI individuals across the country to interact with one another. One activist maintains that Sofia Pride attracts a lot of people who 'like' the event on Facebook but do not attend the parade (Vroom and Antonov 2014). Whilst participating in a virtual community helps individuals to feel safe as well as connected to a wider community, there are disadvantages. Marko Markov, the leader of a youth LGBTI organisation, Deystvie, maintains that the main challenge that the LGBTI movement in Bulgaria faces is 'coming out' (personal interview, 26 June 2015, Sofia). Because the community is largely hidden it means that stereotypes remain unchallenged.

Sofia Gay Pride was held on 28 June 2015 and brought together LGBTI activists and advocates and heterosexual allies in a public celebration. In the week leading up to the parade, there was a photo exhibition and film festival celebrating LGBTI and queer art, and culminated in a showing of the 2014 British movie 'Pride' which documented how the LGBTI community in the UK supported the miners' strike against Thatcher in the 1980s. The parade began with a gathering in Knyazheska Garden, Sofia at the Soviet Army monument. In previous years, attendees on their way to (and returning from) pride had been attacked by neo-Nazis and nationalists so there was a very heavy and visible police presence on every corner and street leading to Knyazheska Garden and all around the park, armoured vehicles were dotted around and police on horseback patrolled the perimeter. The area around the Soviet Army monument was cordoned off and admittance was granted by security. Once inside volunteers gave out hand-held rainbow flags, which is the most visible articulation of LGBTI identity and a potent protest aesthetic. Outside the cordon, rainbow flags were not prominent but inside rainbow flags were flying proudly and some pride protestors scaled the monument and unfurled larger rainbow flags and ribbons whilst dancing. Around 1000 participants eventually gathered and listened to a number of speeches from the main stage, which too, was covered in rainbow balloons. There was a significant media presence with a number of TV channels interviewing 
some protestors and a bank of photographers focusing their lens on the celebratory atmosphere. When a drag queen sashayed up the gardens towards the stage and monument, dozens of photographers fixed their lenses on her. Media outlets are typically interested in the clichéd visual culture of pride parades.

After a number of speeches from activists, including some international activists who had made the trip, foreign embassy representatives and smaller political party representatives, the pride parade began and moved through part of Sofia's centre led by a truck with dance music playing and various people on board dancing. Behind the truck which set the pace various groups and individuals carried different banners, for example, one banner called for an end to homophobia and transphobia, whilst a member of Amnesty International held a banner drawing attention to the murder of student Mihail Stoyanov in 2008 in a Sofia park because he was gay. The loud and highly visible parade generated a lot of attention with members of the public taking photos and people in cafes and restaurants craning their necks to see the parade in its carnivalesque glory. Overall the reception was positive, or at least, not negative. A few people watching the parade go past made their dissatisfaction known but the protestors continued dancing and smiling and were not drawn into confrontation. I saw one group of young men who were quickly intercepted by police before any trouble arose. The police numbered around $200-250$ in total and flanked the pride protestors for the whole of the route. The main issue that some of the public seemed to have with the parade was that it was stopping traffic and impeding mobility around that part of the city. The parade lasted around 30 minutes and found its way back to Knyazheska Garden for more performances on the stage.

Stanimir Panayotov, an activist with Social Centre 'Xaspel' and a former organiser of Sofia Pride, maintains that internal homophobia is an issue in Sofia and notes that people, particularly for younger LGBTI people, are more visible on the internet and everyday online communication rather than in terms of organised political action (Personal Interview 22 June 2015). This suggests that people are more willing to be 'out' online but are not really 'proud', or indeed if this is a concept which is familiar to those coming together online. This makes the public visibility through pride parades all the more important to affirm sexual identity in a public space. Panayotov argues that pride parade is important for visibility because 'visibility is a crucial issue ...the power of visibility' because 'for one day where people see the varied profile of what is an LGBT community, emasculated boys, feminine girls, feminine boys...to see the whole of it.' Tellingly this is about the majority society and how the LGBTI community is perceived and understood. As a hidden society within Bulgaria, this is one of the few opportunities to celebrate and affirm a collective identity. Marko Markov maintains that 'visibility is the main tool to fight homophobia' but believes there is no LGBT community in Bulgaria, rather there are different LGBTI individuals (personal interview 26 June 2015, Sofia). For example, in reaction to the murder of Mihail Stoyanov, some LGBTI activists tried to organise a protest at the park where he was killed and only 50 people turned up. Pride is a one-off annual event but it reveals a public solidarity through a performance of citizenship.

\section{Citizenship, Visibility and Public Space}

Whilst Roma and LGBTI individuals are able to access citizenship rights, societal attitudes towards both communities are overwhelmingly negative with the result that their identities remain hidden and are often perceived by the majority as deviant and potentially threatening 
to the moral fabric of the nation. Communities which are marginalised often prefer to remain out of the gaze of the majority, concerned that they could be used by mainstream politicians and the media to generate fear and revulsion, which could lead to further marginalisation. Roma and LGBTI communities have recently begun to appropriate public space in order to ensure visibility and presence in the public sphere. Both Gay Pride and Roma Pride signify an affirmation of a group identity as a marginalised minority community. Pride is more than merely publicly celebrating an identity but carries with it a performance of citizenship and a declaration of belonging in the public sphere. For one day in a highly visible public arena, these marginalized communities emerge to become visible, in order to remind the majority that they exist and they have rights and interests. Roma Pride was highly visible but the target audience was tourists for the most part and the event was celebratory throughout whilst careful to draw attention to anti-Roma prejudice. Gay Pride was celebratory but carried an air of defiance given the prevalence of anti-gay discourse in the media, from politicians and from the church. Both parades are political as they demonstrate the participation of minority communities in the mainstream public space, even if only for a moment. The impact of the parade on individual participants is empowering and liberating and anchors Roma and LGBT individuals in the broader citizenship regime.

There is a danger that celebrating a marginalised identity generates hostility from the majority meaning visibility in the public sphere will not always yield a positive outcome. We have seen in the past, particularly in the case of gay prides that there has been a backlash usually from conservative elements in society, the church and right-wing nationalists. One could very well argue that the purpose of pride parades is not necessarily to change the hearts and minds of conservative elements of a society but to appeal to moderate people and to highlight the unequal citizenship of Roma and LGBTI individuals. Moderate people could side with LGBTI groups as violent counter movements show themselves to defy public morals more than LGBT people. All performances require an audience and it could be argued that the participation of marginalised groups in pride parades has more than a domestic audience but also a transnational and international audience as international activists and advocates represent a symbolic and sometimes financial resource for LGBTI and Roma groups across Central and Eastern Europe.

\section{Conclusion}

The appropriation of public space by Roma and LGBTI communities is an act of citizenship which simultaneously affirms a collective solidarity and signifies a moment of participation for marginalised communities. Through pride parades, individuals and communities belonging to a minority identity, draw attention to their existence and demand recognition from the majority. Those participating in pride parades do not have a clear outcome or goal which they seek to achieve, rather they are publicly affirming a collective group identity, one which is stigmatised. A lack of presence in public life is the product of fear, oppression, and internalised prejudice and can point to self-censorship in the elaboration of identity or the invisibilising of Roma and LGBTI individuals/citizens through a lack of representation in political debates and marginalised sociocultural status (Ross 2008: 241). Presence means that Roma and LGBTI communities cannot be ignored. But there are differences between Roma and LGBTI communities not least the fact that Roma are highly visibilised with negative 
stereotypes proliferating in the media and in societal attitudes but Roma do not control the representation of group identity and need to find ways to destabilise dominant discourses and representations. LGBTI communities are much more hidden and many individuals in Bulgaria chose to negotiate and sustain their sexual identity online rather than through political mobilisation. Visibility alone is not enough as being visible can lead to more systematic discrimination. Roma and LGBTI communities become visible by appropriating public space and using space to make claims of recognition and belonging through the active participation in the public sphere. This is acutely important in post-socialist Europe where the capacity of citizens to access full citizenship has been compromised at times and thus points to more fruitful avenues of democratic progress which benefits all citizens.

\section{Acknowledgements}

My thanks to Timofey Agarin, Phillip Ayoub and Pawel Karolewski for their comments and suggestions.

\section{References}

Akcali, Emel. and Korkut, Umut. 2015. Urban transformations in Istanbul and Budapest: Neoliberal Governmentality in the EU's semi-periphery and its limits. Political Geography, 46: 76-88.

Amnesty International. 2012. Changing Laws, Changing Minds: Challenging Homophobic and Transphobic Hate Crimes in Bulgaria.

Ayoub, P. (2014) With Arms Wide Shut: Threat Perception, Norm Reception, and Mobilized Resistance to LGBT Rights. Journal of Human Rights, 13(3): 337-362.

Ayoub, P. (2015) Contested Norms in New Adopter States: International Determinants of LGBT Rights Legislation. European Journal of International Relations, 21(2): 293-322.

Ayoub, P. and Paternotte, D. (eds.) 2014. LGBT Activism and the Making of Europe. A Rainbow Europe? Palgrave.

BBC. 2013. Russian Duma Passes Law Banning 'Gay Propaganda'. http://www.bbc.co.uk/news/world-europe-22862210 (Accessed 04.07.15).

Berland, L. and Warner, M. 2003. Sex in Public. In: R. Corber and S. Valocchi (Eds) Queer Studies: An Inter-Disciplinary Reader. Oxford: Blackwell: pp. 170-186.

Bulgarian Helsinki Committee. 2014. Thousand Participants Marched at Sofia Pride 2014, Press Release $8^{\text {th }}$ July. http://www.ilga-

europe.org/home/guide europe/country by country/bulgaria/thousand participants mar ched at sofia pride 2014 
Dittrich, Boris. 2012. Bulgaria: "Chilling" calls for stoning of LGBT citizens in Bulgaria. Human Rights Watch. 28 ${ }^{\text {th }}$ June. http://www.hrw.org/news/2012/06/28/bulgaria-chilling-callsstoning-lgbt-citizens-bulgaria Accessed 28.06.15

European Commission. 2008. Discrimination in the European Union: Perception, Experiences and Attitudes. Eurobarometer. Brussels: Directorate General Employment, Social Affairs and Equal Opportunities.

European Grassroots Antiracist Movement. (EGAM) 2011a. Roma Pride 2011: Overview of Initiatives Throughout Europe. http://egam-eu.blogspot.com/2011/09/roma-pride-2011overview-of-initiatives.html (Accessed 21.7.2015).

European Grassroots Antiracist Movement. (EGAM) 2011b. Roma, Racism, Europe: "Dosta !", and Roma Pride. Manifesto. http://egam-eu.blogspot.com/2011/09/roma-racismeurope-dosta-and-roma-pride.html (Accessed 22.7.2015).

Fremlova, L. and Georgescu, M. 2014. Barrabaripen / Equality: Young Roma Speak about Multiple Discrimination. Council of Europe: Strasbourg.

Fundamental Rights Agency, 2013

Gamson, Joshua. 1995. Must Identity Movements Self-Destruct? A Queer Dilemma. Social Problems, 42(3): 390-407.

Greenwell, Garth. 2013. LGBT Pride and Protest: A First Hand Report from Sofia, Bulgaria. Towleroad $23^{\text {rd }}$ June. http://www.towleroad.com/2013/06/a-report-from-sofiabulgaria.html Accessed 24.07.15

Guglielmo, R. and Waters, W. 2005. Migrating Towards Minority Status: Shifting European Policy Towards Roma. Journal of Common Market Studies, 43(4): 763-785.

Harvey, David. 1996

Holzhacker, R. 2013. State-Sponsored Homophobia and the Denial of the Right of Assembly in Central and Eastern Europe: The 'Boomerang' and the 'Riccohet' between European Organizations and Civil Society to Uphold Human Rights. Law and Policy 35(1-2): 1-25.

Isin, Engin. and G. Nielsen 2008. Acts of Citizenship. Zed: London.

Kahlina, Katja. 2013. Contested terrain of Sexual Citizenship: EU Accession and the Changing Position of Sexual Minorities in the Post-Yugoslav Context, CITSEE Working Paper 33, Edinburgh. 
Karolewski, Ireneusz Pawel. 2010. Citizenship and Collective Identity in Europe. Abington: Routledge.

Kärrholm, Matthias. 2007. A Conceptual Discussion of Territoriality, Materiality and the Everyday Life of Public Space, Space and Culture 10(4): 437-453.

Lakhani et al 2014

Littauer, Dan. 2014. Bulgaria's Main Nationalist Party Proposes to Outlaw Gay Pride Events. Huffington Post. $7^{\text {th }}$ February. http://www.huffingtonpost.co.uk/dan-littauer/gay-pridebulgaria b 4743399.html Accessed 28.04.15.

Loftland, L. 1998. The Public Realm. New York. Aldine de Gruyters.

Martsenyuk, Tamara. 2012. The State of the LGBT Community and Homophobia in Ukraine, Problems of Post Communism 59(2): 51-62.

Massey, Doreen. 1998. The Spatial Construction of Youth Cultures in T. Skelton and G. Valentine (eds) Cool Places: Geographies of Youth Cultures, pp. 121-129. London, Routledge.

McGarry, A. 2010. Who Speaks for Roma? Political Representation of a Transnational Minority Community. London: Continuum.

McGarry, A. 2014. Roma as a Political Identity: Exploring Representations of Roma in Europe, Ethnicities, 14(6): 756-774.

McGarry, A. and Agarin, T. 2014. Unpacking the Roma Participation Puzzle: Voice, Presence and Influence, Ethnic and Migration Studies, 40(12): 1972-1990.

McGarry, A. and Jasper, J. (eds.) (2015) The Identity Dilemma: Social Movements and Collective Identity. Philadephia, PA; Temple University Press.

Melucci, Alberto. 1989. Challenging Codes: Collective Action in Information Age. Cambridge: Cambridge University Press.

Mudeva, Anna. 2008. About 60 arrested at Bulgaria's first Gay Parade. Reuters, $28^{\text {th }}$ June. http://www.reuters.com/article/2008/06/28/us-bulgaria-gays-idUSL2858989620080628

O'Dwyer, Conor. 2012. Does the EU Help or Hinder Gay-Rights Movements in Post-communist Europe? The Case of Poland, East European Politics 28 (4): 332-352.

Painter, Joe. 2010. Rethinking Territory, Antipode, 42(5): 1090-1118.

Phillips, Ann. 1998. The Politics of Presence. Oxford: Oxford University Press.

Pickering, Jonny, Kintrea, Keith, and Bannister, Jon. 2011. Invisible Walls and Visible Youth: Territoriality among Young People in British Cities, Urban Studies, 49(5): 945-960. 
Plaut, Shayna. 2012. Expelling the Victim by Demanding Voice: The Counter-framing of Transnational Romani Activism. Alternatives: Global, Local, Political 37(1): 52-65.

Ringold, D., Orenstein, M. and Wilkens, E. 2005. Roma in an Expanding Europe: Breaking the Poverty Cycle. World Bank: Washington.

Ross, Charlotte. 2008. Visions of Visibility: LGBT Communities in Turin. Modern Italy 13(3): 241-260.

Sack, Robert. 1986. Human Territoriality. Cambridge: Cambridge University Press.

Soros, George. 2011. George Soros message for the "Me sem rom, me sem romni". http://www.youtube.com/watch?feature=player embedded\&v=dTHwKg7omwE\#!

(Accessed 21.4.2015)

Stewart, Michael. 1997. The Time of the Gypsies. Westview:

Tatchell, Peter. 2009. Slavic Pride: Thank You Mayor Luzhkov by Peter Tatchell , The Guardian, Comment is Free. May $19^{\text {th }}$.

Tarrow, S. 2005. The New Transnational Activism. Cambridge: Cambridge University Press.

Underwood, Alice. 2011. The Politics of Pride: The LGBT Movement and Post-Soviet Democracy. Harvard International Review, Spring. 42-46.

Ungar, Mark. 2000. State Violence and Lesbian Gay, Bisexual and Transgender (LGBT) Rights, New Political Science, 22:1: 61-75.

Vroom, Rosa and Antonov, Pavel. 2014. Bulgaria: Divided Movements, Divided Rights. Global Information Society Watch, 80-83.

\footnotetext{
'The term "Roma" used at the Council of Europe refers to Roma, Sinti, Kale and related groups in Europe, including Travellers and the Eastern groups (Dom and Lom), and covers the wide diversity of the groups concerned, including persons who identify themselves as Gypsies. Roma are present across Europe though are mostly located in Central and Eastern European states. They number approximately 10-12 million and are regarded as one of the most marginalised and persecuted minority groups in Europe.

ii LGBTI refers to persons identifying as lesbian, gay, bisexual, trans, and/or intersex. Whilst I discuss the LGBTI community in Central and Eastern Europe in this article, it principally focuses on the Lesbian and Gay experience as bi, trans and intersex people are largely invisible in many pride events here, and their own experience of visibility varies a great deal. For example, trans people are highly visible on an individual basis (such as on the street) but have only recently begun to achieve some of the public visibility that lesbians and gay men have been developing for the past 2-3 decades. Indeed, intersex people are almost entirely absent from movements in Central and Eastern Europe, including in name.

iii There are those who identify as LGBTI Roma across Europe but this article focuses on Roma Pride and LGBT Pride not the intersections between the two. For further reading on LGBTI Roma, please see Fremlova and Georgescu 2014.
} 
iv Mobilisation on the basis of a supposedly coherent identity is not without its problems and necessitates a negotiation of the 'identity dilemma' (see McGarry and Jasper 2015).

$\checkmark$ In quantitative analysis exploring 'unwanted neighbours', in the Czech Republic attitudes towards Roma were the most negative out of the 35 countries examined with $80.5 \%$ of people saying they would rather not have Roma as a neighbour. In Bulgaria, $59.8 \%$ of people did not want a homosexual as a neighbour (Lakhani et al 2014: 45).

vi There is an argument that Russia is an exception to the rule here. Russia actively uses the LGBTI issue to distinguish itself from "the West" culturally enacting punitive legislation which is out of step with Central and Eastern Europe.

vii It is important to remember that there are many avenues of visibility open to LGBTI individuals and communities including visual aesthetics such as clothing but also the existence of NGOs. Roma individuals are sometimes more visible in public space due to style of dress or skin colour, but also place of residence and profession. Diverse avenues mean that visibility can be more sustained. 